\title{
Positive correlation of serum adipocyte fatty acid binding protein levels with carotid-femoral pulse wave velocity in geriatric population
}

\author{
Jen-Pi Tsai ${ }^{1,2}$, Ji-Hung Wang ${ }^{2,3}$, Chung-Jen Lee ${ }^{4}$, Yu-Chih Chen ${ }^{3}$ and Bang-Gee Hsu ${ }^{2,5^{*}}$
}

\begin{abstract}
Background: Adipocyte fatty acid binding protein (A-FABP) is a novel fat-derived circulating protein, which is independently and positively associated with atherosclerosis. The present study evaluated the relationship between fasting serum A-FABP and central arterial stiffness in geriatric adults.

Methods: Fasting blood samples were obtained from 87 geriatric patients and the serum A-FABP levels were measured using an enzyme immunoassay. Carotid-femoral pulse wave velocity (cfPWV) was determined using the SphygmoCor system. cfPWV values of $>10 \mathrm{~m} / \mathrm{s}$ represented the high arterial stiffness group, while values $\leq 10 \mathrm{~m} / \mathrm{s}$ defined the low arterial stiffness group.

Results: High arterial stiffness group comprised of 42 geriatric adults (48.3\%). When compared to those in the low arterial stiffness group, the high arterial stiffness group had a higher rate of diabetes mellitus $(P=0.044)$ and hypertension $(P=0.043)$. Body weight $(P=0.027)$, waist circumference $(P=0.035)$, body mass index $(P=0.001)$, systolic blood pressure $(P=0.005)$, diastolic blood pressure $(P=0.045)$, pulse pressure $(P=0.038)$, and serum A-FABP level $(P<0.001)$ were also higher in the high arterial stiffness group than in the low arterial stiffness group. Multivariate logistic regression analysis of the factors significantly associated with arterial stiffness revealed that A-FABP (odds ratio: 1.833, $95 \%$ confidence interval 1.123-2.993, $P=0.015$ ) was an independent predictor of arterial stiffness in geriatric adults.
\end{abstract}

Conclusions: Serum A-FABP levels constitute a major risk factor in the development of central arterial stiffness in the geriatric population.

Keywords: Adipocyte fatty acid binding protein, Arterial stiffness, Geriatric adults, Pulse wave velocity

\section{Background}

Vessel stiffness is one of the multiple characteristics of cardiovascular (CV) disease, including abnormalities like, the thickening of the vessel wall, formation of fatty streaks, atherosclerotic plaques, and coronary artery calcification [1]. Arterial stiffness is being increasingly recognized as a surrogate end point for CV diseases [2]. The mechanism of arterial stiffness most often involves, degradation of elastin fibers, collagen accumulation, reorganization of cellular elements, and low-grade inflammation with increased expression of tumor necrosis

\footnotetext{
* Correspondence: gee.lily@msa.hinet.net

${ }^{2} \mathrm{~S} c h$ ool of Medicine, Tzu Chi University, Hualien, Taiwan

${ }^{5}$ Division of Nephrology, Buddhist Tzu Chi General Hospital, No. 707, Section 3, Chung-Yang Road, Hualien 97002, Taiwan

Full list of author information is available at the end of the article
}

factor-alpha, interleukin-6 and high-sensitivity C-reactive protein $[3,4]$. Arterial stiffness reflects sub-clinical organ damage and is considered an important predictor of $\mathrm{CV}$ disease. The carotid-femoral pulse wave velocity (cfPWV) is a recommended measure to determine arterial stiffness [5]. A systematic review showed that aortic PWV is a strong predictor of future $\mathrm{CV}$ events and all-cause mortality, and has a predictive value independent of classic potential CV risk factors [2].

Aberrant production of the adipokines, due to adiposopathy (fat dysfunction), is an important risk factor for the development of obesity-related CV diseases. Adipocyte fatty acid binding protein (A-FABP), a polypeptide with 132 amino acids and a molecular mass of $14.6 \mathrm{kDa}$, is one of the most abundant proteins in mature adipocytes, 
accounting for about $6 \%$ of their total cellular protein content [6]. A-FABP mRNA and protein production are elevated in subcutaneous adipose tissue, as compared to the visceral depot in lean and obese individuals [7]. A-FABP overproduction is believed to play a central role in obesity-related $\mathrm{CV}$ disease and endothelial dysfunction by increasing cholesterol and triglyceride accumulation, leading to foam cell development and induction of pro-inflammatory genes. This will in turn promote insulin resistance, atherosclerosis, and potentiate lipid-induced impairment in the activation of endothelial nitric oxide synthase (eNOS) [8].

Previously, we had reported that A-FABP was associated with metabolic syndrome in patients with coronary artery disease and in hemodialysis patients $[9,10]$. In addition, arterial stiffness was reported to increase with age. The low prevalence of atherosclerosis in East Asian populations, suggests that the stiffness of arteries was an inevitable consequence of aging [11]. Since CV diseases are a major cause of mortality in the geriatric population, with adipokines playing an important role, we conducted this study to exclude the influences of aging on arterial stiffness. The present study examined the various risk factors in the development of arterial stiffness and evaluated the correlation between the serum concentration of A-FABP and arterial stiffness in geriatric adults.

\section{Methods}

\section{Participants}

Eighty seven elderly volunteers, aged 65 years or older, were enrolled into this study between January and December 2012, at a medical center in Hualien, eastern Taiwan. Trained staff measured blood pressure (BP) in the morning for all participants, using standard mercury sphygmomanometers with appropriate cuff sizes, after the participants had been sitting for at least $10 \mathrm{~min}$. Systolic blood pressure (SBP) and diastolic blood pressure (DBP) were taken at points of appearance and disappearance of the Korotkoff sounds, respectively. SBP and DBP were taken three times at 5-min intervals and were averaged for analysis. Pulse pressure was calculated by subtracting DBP from SBP. In the prevalence survey, hypertension (HTN) was defined as SBP $\geq 140 \mathrm{mmHg}$, and/or DBP $\geq 90 \mathrm{mmHg}$, or prescription of antihypertensive medication in the past 2 weeks. A person was regarded as having diabetes mellitus (DM), if the fasting plasma glucose was either $126 \mathrm{mg} / \mathrm{dL}$ or more, or if he/ she was using diabetes medication (oral or insulin) [12]. The current study was approved by the Institutional Review Board of Tzu-Chi University and Hospital. Participants were excluded from the study, if they had an acute infection, acute myocardial infarction, or pulmonary edema at the time of blood sampling, or in case of any reported use of calcium, active vitamin D metabolites, bisphosphonates, teriparatide, or estrogens medication, or if they declined to provide written informed consents for the study.

\section{Anthropometric analysis}

Body weight was measured in patients wearing light clothing and without shoes, to the nearest 0.5 kilograms, and height was measured to the nearest $0.5 \mathrm{~cm}$. Waist circumference was measured by tape around the patient's waist, from the point of the lowest ribs to the hip bones by placing patient's hands on hips. Body mass index (BMI) was calculated as the weight in kilograms divided by the height in meters squared [13].

\section{Biochemical investigations}

Fasting blood samples (approximately $5 \mathrm{~mL}$ ) were collected and immediately centrifuged at $3000 \mathrm{~g}$ for $10 \mathrm{~min}$. Serum levels of blood urea nitrogen (BUN), creatinine (Cre), fasting glucose, total cholesterol ( $\mathrm{TCH})$, triglycerides (TG), high-density lipoprotein cholesterol (HDL-cholesterol), low-density lipoprotein cholesterol (LDL-cholesterol), total calcium, and phosphorus, were measured using an autoanalyzer (COBAS Integra 800, Roche Diagnostics, Basel, Switzerland) [13-15]. Serum A-FABP levels were measured using a commercially available enzyme immunoassay (EIA; SPI- BIO, Montigny le Bretonneux, France) $[9,10]$. Serum intact parathyroid hormone levels (iPTH) were measured using enzyme-linked immunosorbent assays (ELISA; Diagnostic Systems Laboratories, Webster, Texas, USA) [15]. The estimate glomerular filtration rate (GFR) was calculated in this study using the Modification of Diet in Renal Disease (MDRD) equation.

\section{Carotid-femoral pulse wave velocity (cfPWV) measurements}

The cfPWV were measured using a pressure tonometer (SphygmoCor system, AtCor Medical, Australia), and the pressure pulse waveform in the underlying artery was recorded transcutaneously, as previously described $[14,15]$. All measurements were taken in the morning while the participants are in a supine position, after a minimum of $10-\mathrm{min}$ rest in a quiet, temperaturecontrolled room. Records were made simultaneously with an ECG signal, which provided an $R$-timing reference. Pulse wave recordings were performed consecutively at two superficial artery sites (carotid-femoral segment). Integral software was used to process each set of the pulse wave and ECG data, to calculate the mean time difference between the $R$-wave and the pulse wave on a beat-to-beat basis, with an average of ten consecutive cardiac cycles. The cfPWV was calculated using the distance and the mean time difference between the two recorded points. Quality indices, included in the software, were set to ensure the uniformity of data. In this study, 
cfPWV values of $>10 \mathrm{~m} / \mathrm{s}$ were used to define the high arterial stiffness group, while values $\leq 10 \mathrm{~m} / \mathrm{s}$ were regarded as the low arterial stiffness group, according to the ESHESC 2013 Guidelines [5].

\section{Statistical analysis}

Data are expressed as the mean \pm standard deviation (SD) and were tested for normal distribution using Kolmogorov-Smirnov statistics. Comparisons between patients were performed using the Student's independent $t$-test (2-tailed) for normally distributed data, or the Mann-Whitney $U$ test for parameters that presented a non-normal distribution (TG, fasting glucose, and iPTH). Data expressed as the number of patients were analyzed by the $\chi^{2}$ test. Variables that were significantly associated with arterial stiffness in geriatric adults were tested for independence by multivariate logistic regression analysis (adapted factors: DM, HTN, body weight, waist circumference, BMI, SBP, DBP, pulse pressure, and A-FABP). Data were analyzed using SPSS for Windows (version 19.0; SPSS Inc., Chicago, IL, USA). A P-value $<0.05$ was considered statistically significant.

\section{Results}

Demographic, biochemical, and clinical characteristics of the 87 geriatric adults are shown in Tables 1 and 2. The medical histories of the geriatric adults included DM $(n=34$ [39.1\%]), and HTN $(n=42$ [48.3\%]). The medications prescribed to the geriatric adults included angiotensin-converting enzyme inhibitors (ACEi; $n=13$ [14.9\%]), angiotensin receptor blockers (ARB; $n=30$ [34.5\%]), $\beta$-blockers $(n=24$ [27.6 \%]), calcium channel blockers (CCB; $n=22[25.3 \%])$, statins $(n=28$ [32.2\%]), and fibrate $(n=10[11.5 \%])$. Forty-two geriatric adults
(48.3\%) belonged to the high arterial stiffness group, and when compared to the geriatric adults in the low arterial stiffness group, they had a higher incidence of DM (31.1\% vs. $52.4 \%, P=0.044$ ) or HTN ( $37.8 \%$ vs. $59.5 \%, P=0.043$ ). There was no statistically significant difference between the high and low arterial stiffness groups, based on, gender, $\mathrm{ACEi}, \mathrm{ARB}, \beta$-blocker, $\mathrm{CCB}$, statins, or fibrate use.

Body weight $(67.37 \pm 10.91 \mathrm{~kg}$ vs. $62.40 \pm 9.69 \mathrm{~kg}$, $P=0.027)$, waist circumference $(93.79 \pm 11.99 \mathrm{~cm}$ vs. $88.91 \pm 9.10 \mathrm{~cm}, P=0.035)$, BMI $\left(26.63 \pm 3.83 \mathrm{~kg} / \mathrm{m}^{2}\right.$ vs. $\left.24.04 \pm 3.21 \mathrm{~kg} / \mathrm{m}^{2}, \quad P=0.001\right), \quad$ SBP $(137.40 \pm$ $18.68 \mathrm{mmHg}$ vs. $126.69 \pm 15.77 \mathrm{mmHg}, P=0.005)$, DBP $(73.26 \pm 7.71 \mathrm{mmHg}$ vs. $69.53 \pm 9.27 \mathrm{mmHg}, P=0.045)$, pulse pressure $(64.14 \pm 16.54 \mathrm{mmHg}$ vs. $57.16 \pm$ $14.42 \mathrm{mmHg}, P=0.038$ ) were higher in the high arterial stiffness group, as compared to the low arterial stiffness group. Moreover, serum A-FABP was also elevated in the high arterial stiffness group than in the low arterial stiffness group $(28.13 \pm 13.86 \mathrm{ng} / \mathrm{ml}$ vs. $17.69 \pm 11.01 \mathrm{ng} / \mathrm{ml}$, $P<0.001$; Table 3).

Multivariate logistic regression analysis of the factors significantly associated with arterial stiffness (DM, HTN, body weight, waist circumference, BMI, SBP, DBP, pulse pressure, and A-FABP) revealed that A-FABP (odds ratio: $1.833,95 \%$ confidence interval (CI): 1.123-2.993, $P=0.015)$ was an independent predictor of arterial stiffness in geriatric adults (Table 4).

\section{Discussion}

The current results reveal that the fasting A-FABP levels were higher in the high arterial stiffness group than in the low arterial stiffness group, and A-FABP is an independent predictor for the development of arterial stiffness in the geriatric population.

Table 1 Clinical and analytical characteristics of 87 geriatric adults

\begin{tabular}{|c|c|c|c|c|}
\hline \multirow{2}{*}{$\begin{array}{l}\text { Items } \\
\text { Anthropometric findings }\end{array}$} & \multicolumn{2}{|l|}{ Parameter } & \multicolumn{2}{|l|}{ Parameter } \\
\hline & Height $(\mathrm{cm})$ & $160.08 \pm 7.81$ & Waist circumference (cm) & $91.26 \pm 10.81$ \\
\hline & Body weight (kg) & $64.80 \pm 10.54$ & & $72.18 \pm 5.36$ \\
\hline & Body mass index $\left(\mathrm{kg} / \mathrm{m}^{2}\right)$ & $25.29 \pm 3.74$ & Age (year) & $131.86 \pm 17.96$ \\
\hline & $\mathrm{DBP}(\mathrm{mmHg})$ & $71.33 \pm 8.71$ & $\mathrm{SBP}(\mathrm{mmHg})$ & $60.53 \pm 15.78$ \\
\hline & & & Pulse pressure $(\mathrm{mmHg})$ & \\
\hline \multirow[t]{7}{*}{ Biochemical findings } & Triglyceride (mg/dL) & $133.87 \pm 78.34$ & Total cholesterol (mg/dL) & $174.44 \pm 36.56$ \\
\hline & Fasting glucose (mg/dL) & $126.30 \pm 44.67$ & HDL-cholesterol (mg/dL) & $47.28 \pm 12.74$ \\
\hline & LDL-cholesterol (mg/dL) & $103.84 \pm 34.33$ & Creatinine (mg/dL) & $1.19 \pm 0.37$ \\
\hline & BUN (mg/dL) & $17.97 \pm 6.31$ & GFR (mL/min) & $64.53 \pm 20.17$ \\
\hline & Total calcium (mg/dL) & $9.13 \pm 0.38$ & Phosphorus (mg/dL) & $3.44 \pm 0.38$ \\
\hline & $\mathrm{Ca} \times \mathrm{P}$ product $\left(\mathrm{mg}^{2} / \mathrm{dL}^{2}\right)$ & $31.39 \pm 4.46$ & iPTH (pg/mL) & $58.31 \pm 34.53$ \\
\hline & A-FABP $(n g / m L)$ & $22.73 \pm 13.46$ & $\mathrm{cfPWV}(\mathrm{m} / \mathrm{s})$ & $10.13 \pm 2.92$ \\
\hline
\end{tabular}

Data are expressed as means \pm standard deviations

SBP systolic blood pressure, DBP diastolic blood pressure, HDL-cholesterol high-density lipoprotein cholesterol, $L D L$-cholesterol low-density lipoprotein cholesterol, $B U N$ blood urea nitrogen, GFR glomerular filtration rate, $C a \times P$ product calcium-phosphorus product, $i P T H$ intact parathyroid hormone, $A$-FABP adipocyte fatty acid binding protein, cfPWV carotid-femoral pulse wave velocity 
Table 2 Clinical characteristics and carotid-femoral pulse wave velocity levels of 87 geriatric adults

\begin{tabular}{lllll}
\hline Characteristic & & Low AS group (\%) & High AS group (\%) & $P$ value \\
\hline Gender & Male & $31(68.9)$ & $29(69.0)$ & 0.897 \\
& Female & $14(31.1)$ & $13(31.0)$ & \\
Diabetes & No & $31(68.9)$ & $20(47.6)$ & $0.044^{*}$ \\
& Yes & $14(31.1)$ & $22(52.4)$ & \\
Hypertension & No & $28(62.2)$ & $17(40.5)$ & $0.043^{*}$ \\
& Yes & $17(37.8)$ & $25(59.5)$ & \\
ACE inhibitor & No & $41(91.1)$ & $35(83.3)$ & 0.275 \\
& Yes & $4(8.9)$ & $7(16.7)$ & \\
ARB & No & $33(73.3)$ & $24(57.1)$ & 0.112 \\
\multirow{3}{*}{$\begin{array}{l}\text { B-blocker } \\
\text { Yes }\end{array}$} & $12(26.7)$ & $18(42.9)$ & \\
& No & $35(77.8)$ & $28(66.7)$ & 0.247 \\
CCB & Yes & $10(22.2)$ & $14(33.3)$ & \\
& No & $36(80.0)$ & $29(69.0)$ & 0.240 \\
Statins & Yes & $9(20.0)$ & $13(31.0)$ & \\
& No & $29(64.4)$ & $30(71.4)$ & 0.486 \\
Fibrate & Yes & $16(35.6)$ & $12(28.6)$ & \\
& No & $40(88.9)$ & $37(88.18)$ & 0.908 \\
& Yes & $5(11.1)$ & $5(11.9)$ & \\
\hline Data & & &
\end{tabular}

Data are expressed as number of patients and analysis was done using the $x^{2}$ test

$A S$ arterial stiffness, cfPWV carotid-femoral pulse wave velocity, $A C E$ angiotensin-converting enzyme, $A R B$ angiotensin-receptor blocker, $C C B$ calcium-channel blocker

${ }^{*} P<0.05$ was considered statistically significant after Student $t$-test

A systematic review had shown that BP was independently associated with PWV in approximately $90 \%$ of the studies [16]. Cecelja et al. found a dissociation of cfPWV with classic factors, such as gender, smoke, or lipids other than HTN, and they suggested that aortic stiffing might be driven by an alternative pathology, which depended on mechanical stretch of the arterial wall [16]. The pathophysiological correlation between arterial stiffness and HTN is that the increased arterial stiffness reduces the lumen diameter, for a given smooth muscle tone and blood pressure, leading to a premature return of the reflected wave in late systole, thereby increasing the central pulse pressure and SBP, and decreasing DBP [17]. On the other hand, aortic stiffness may affect aortic function, reduce baroreceptor responsiveness, and increase systolic pressure, making arterial stiffness one of the leading causes of increased blood pressure [4]. Meta-analysis of studies in the field have demonstrated that an increase in aortic PWV by $1 \mathrm{~m} / \mathrm{s}$ corresponded to an age-, sex-, and risk factor-adjusted increase in total $\mathrm{CV}$ events, $\mathrm{CV}$ mortality, and all-cause mortality by 14,15 , and $15 \%$, respectively [2]. In addition, another meta-analysis found that greater arterial stiffness correlated with cerebral small vessel diseases [18], and Zhang et al. supposed that
Table 3 Clinical variables of the 87 geriatric adults with or without arterial stiffness

\begin{tabular}{|c|c|c|c|}
\hline Items & $\begin{array}{l}\text { Low AS group } \\
(n=45)\end{array}$ & $\begin{array}{l}\text { High AS group } \\
(n=42)\end{array}$ & $P$ value \\
\hline$\overline{\text { Age }(\text { years })^{a}}$ & $71.71 \pm 5.36$ & $72.69 \pm 5.38$ & 0.397 \\
\hline Height $(\mathrm{cm})^{\mathrm{a}}$ & $161.02 \pm 7.54$ & $159.07 \pm 8.04$ & 0.246 \\
\hline Body weight $(\mathrm{kg})^{\mathrm{a}}$ & $62.40 \pm 9.69$ & $67.37 \pm 10.91$ & $0.027^{*}$ \\
\hline Waist circumference $(\mathrm{cm})^{\mathrm{a}}$ & $88.91 \pm 9.10$ & $93.79 \pm 11.99$ & $0.035^{*}$ \\
\hline Body mass index $\left(\mathrm{kg} / \mathrm{m}^{2}\right)^{\mathrm{a}}$ & $24.04 \pm 3.21$ & $26.63 \pm 3.83$ & $0.001^{*}$ \\
\hline $\mathrm{cfPWV}(\mathrm{m} / \mathrm{s})^{\mathrm{a}}$ & $7.89 \pm 1.20$ & $12.50 \pm 2.56$ & $<0.001^{*}$ \\
\hline SBP $(m m H g)^{a}$ & $126.69 \pm 15.77$ & $137.40 \pm 18.68$ & $0.005^{*}$ \\
\hline $\mathrm{DBP}(\mathrm{mmHg})^{\mathrm{a}}$ & $69.53 \pm 9.27$ & $73.26 \pm 7.71$ & $0.045^{*}$ \\
\hline Pulse pressure $(\mathrm{mmHg})^{\mathrm{a}}$ & $57.16 \pm 14.42$ & $64.14 \pm 16.54$ & $0.038^{*}$ \\
\hline Total cholesterol $(\mathrm{mg} / \mathrm{dL})^{\mathrm{a}}$ & $174.69 \pm 31.80$ & $174.17 \pm 41.45$ & 0.947 \\
\hline Triglyceride $(\mathrm{mg} / \mathrm{dL})^{\mathrm{b}}$ & $131.60 \pm 83.17$ & $136.31 \pm 73.74$ & 0.405 \\
\hline $\mathrm{HDL}-\mathrm{C}(\mathrm{mg} / \mathrm{dL})^{\mathrm{a}}$ & $49.60 \pm 12.87$ & $44.78 \pm 12.27$ & 0.078 \\
\hline $\mathrm{LDL}-\mathrm{C}(\mathrm{mg} / \mathrm{dL})^{\mathrm{a}}$ & $102.89 \pm 27.96$ & $104.86 \pm 40.38$ & 0.791 \\
\hline Fasting glucose $(\mathrm{mg} / \mathrm{dL})^{\mathrm{b}}$ & $123.73 \pm 47.51$ & $129.05 \pm 41.82$ & 0.271 \\
\hline Blood urea nitrogen $(\mathrm{mg} / \mathrm{dL})^{\mathrm{a}}$ & $16.76 \pm 5.23$ & $19.26 \pm 7.13$ & 0.064 \\
\hline Creatinine $(\mathrm{mg} / \mathrm{dL})^{\mathrm{a}}$ & $1.13 \pm 0.33$ & $1.26 \pm 0.41$ & 0.108 \\
\hline $\mathrm{GFR}(\mathrm{mL} / \mathrm{min})^{\mathrm{a}}$ & $67.67 \pm 19.18$ & $61.17 \pm 20.87$ & 0.134 \\
\hline Total calcium (mg/dL) & $9.16 \pm 0.40$ & $9.09 \pm 0.37$ & 0.363 \\
\hline Phosphorus (mg/dL) & $3.43 \pm 0.48$ & $3.46 \pm 0.46$ & 0.782 \\
\hline $\mathrm{Ca} \times \mathrm{P}$ product $\left(\mathrm{mg}^{2} / \mathrm{dL}^{2}\right)$ & $31.40 \pm 4.39$ & $31.43 \pm 4.60$ & 0.941 \\
\hline iPTH $(p g / m L)^{b}$ & $56.44 \pm 36.99$ & $60.32 \pm 32.01$ & 0.165 \\
\hline A-FABP $(n g / m L)^{a}$ & $17.69 \pm 11.01$ & $28.13 \pm 13.86$ & $<0.001^{*}$ \\
\hline
\end{tabular}

$A S$ arterial stiffness, cfPWV carotid-femoral pulse wave velocity, SBP systolic blood pressure, $D B P$ diastolic blood pressure, $H D L-C$ high density lipoprotein-cholesterol, $L D L-C$ low density lipoprotein-cholesterol, $G F R$ glomerular filtration rate, $C a \times P$ product calcium-phosphorus product, iPTH intact parathyroid hormone, $A-F A B P$ adipocyte fatty acid binding protein ${ }^{*} P<0.05$ was considered statistically significant after the Student's $t$-test or Mann-Whitney $U$ test

${ }^{\text {a }}$ data were tested using the Student's $t$-test

${ }^{b}$ data were tested using the Mann-Whitney $U$ test

measuring cfPWV was beneficial to the elderly regarding the cardiovascular and cerebrovascular diseases, including atherosclerosis, cognitive dysfunction and mortality [19]. Therefore, arterial stiffness could serve as an independent predictor of coronary events and adverse CV diseases.

Studies had shown that there is a crosstalk between $\mathrm{CV}$ diseases and adipokines, such as, adiponectin, leptin, and A-FABP [20-23]. Makowski and colleagues reported that apolipoprotein $\mathrm{E}$ deficient mice with A-FABP +/+ adipocytes and A-FABP - /- macrophages, showed a comparable reduction in atherosclerotic lesions to those with total A-FABP deficiency, indicating an independent role for macrophage A-FABP in atherogenesis [24]. Lee et al. had shown an enhanced expression of A-FABP on aortic endothelium of apolipoprotein $\mathrm{E}$ deficient mice and in cultured human microvascular endothelial cells. This lipid-induced A-FABP expression was associated 
Table 4 Correlation between arterial stiffness among the 87 geriatric adults by multivariate logistic regression analysis

\begin{tabular}{|c|c|c|c|}
\hline Variables & Odds ratio & $95 \% \mathrm{Cl}$ & $P$ value \\
\hline $\begin{array}{l}\text { A-FABP }(\mathrm{ng} / \mathrm{mL}) \\
\text { (each increase of } 1 \mathrm{ng} / \mathrm{mL} \text { ) }\end{array}$ & 1.833 & $1.123-2.993$ & $0.015^{*}$ \\
\hline Diabetes & 1.737 & $0.621-4.858$ & 0.293 \\
\hline Hypertension & 1.360 & $0.465-3.982$ & 0.575 \\
\hline $\begin{array}{l}\text { Body weight }(\mathrm{kg}) \\
\text { (each increase of } 1 \mathrm{~kg} \text { ) }\end{array}$ & 1.049 & $0.949-1.160$ & 0.351 \\
\hline $\begin{array}{l}\text { Waist circumference }(\mathrm{cm}) \\
\text { (each decrease of } 1 \mathrm{~cm} \text { ) }\end{array}$ & 0.970 & $0.895-1.052$ & 0.463 \\
\hline $\begin{array}{l}\text { BMI }\left(\mathrm{kg} / \mathrm{m}^{2}\right) \\
\left(\text { each increase of } 1 \mathrm{~kg} / \mathrm{m}^{2}\right)\end{array}$ & 1.124 & $0.858-1.472$ & 0.397 \\
\hline $\begin{array}{l}\mathrm{SBP}(\mathrm{mmHg}) \\
\text { (each increase of } 1 \mathrm{mmHg} \text { ) }\end{array}$ & 1.022 & $0.988-1.057$ & 0.207 \\
\hline $\begin{array}{l}\text { DBP }(\mathrm{mmHg}) \\
\text { (each increase of } 1 \mathrm{mmHg} \text { ) }\end{array}$ & 1.023 & $0.956-1.094$ & 0.514 \\
\hline \multicolumn{4}{|c|}{$\begin{array}{l}C \text { l confidence Interval, } A-F A B P \text { adipocyte fatty acid binding protein, } B M I \text { body } \\
\text { mass index, SBP systolic blood pressure, } D B P \text { diastolic blood pressure } \\
{ }^{*} P<0.05 \text { was considered statistically significant in the multivariate logistic } \\
\text { regression analysis (adopted factors: diabetes, hypertension, body weight, } \\
\text { waist circumference, BMI, SBP, DBP, pulse pressure and A-FABP) }\end{array}$} \\
\hline
\end{tabular}

with reduced phosphorylated eNOS and NO production, and was reversed by A-FABP inhibitor [8]. So, the pro-atherogenic potential of A-FABP on the vasculature is possibly mediated by the pro-inflammatory effects, independent of lipid metabolism and insulin sensitivity. Further, it contributes to the endothelial dysfunction by potentiating lipid-induced impairment in eNOS activation, and thus endothelium-dependent vasodilatation.

Clinical reports reveal a significant correlation of baseline serum A-FABP with BMI, homeostasis model of insulin resistance, and cardio-ankle vascular index, which is a marker of arterial stiffness [25, 26]. In addition to the associated metabolic risk factors, A-FABP levels were positively correlated with coronary plaque volume burden as well, and may serve as a biomarker for the detection of coronary artery disease [22, 23]. An increase in the number of stenotic coronary arteries resulted in a corresponding increase in the plasma A-FABP levels in patients with coronary heart diseases [23]. In addition to the macrovascular complications (ischemic heart disease, stroke, or peripheral vascular disease) in diabetic patients, A-FABP show a positive correlation with albuminuria and negative correlation with glomerular filtration rate, indicating that the serum level of A-FABP is influenced by impaired renal clearance and activated macrophages in diabetic nephropathy [27]. In this study, we found that geriatric adults who had high arterial stiffness would have higher serum A-FABP levels than those with low arterial stiffness. Moreover, A-FABP was demonstrated to be an independent risk factor for developing high arterial stiffness.
Classic CV risk factors, including DM, hyperlipidemia, elevated BMI and smoking, had been implicated in accelerating arterial stiffness. However, Cecelja et al. have indicated that the prognostic value of cfPWV may be related to a process of arterial ageing, and probably unrelated to the classic risk factors, other than HTN [16]. Additionally, impaired glucose tolerance and DM in a population-based study was independently associated with the central arterial stiffness, after adjusting mean arterial pressure, age and gender [28]. In our geriatric patients, we found that adults who were found to have high arterial stiffness would have a higher body weight, waist circumference, BMI, SBP, DBP, and pulse pressure. Furthermore, those who were in the high arterial stiffness group also had a higher percentage of DM or HTN, as previously reported [16].

Several types of medications had been demonstrated to affect arterial stiffness. Studies of $\beta$-blockers on arterial stiffness showed less impact on central BP decline compared with the peripheral BP $[29,30]$. Older hypertensive patients treated with calcium channel blockers, showed the lowest central aortic pressure and less augmentation pressure, when compared with the placebo [31]. Moreover, usage of ACEi or ARB showed significant effects on reducing the central $\mathrm{BP}$ and augmentation index, through the reduction of oxidative stress and inflammation, and vasodilatation through angiotensin II inhibition [30, 31]. Miyoshi et al. conducted a study which showed that the effects of ARB in HTN patients could reduce cardio-ankle vascular index as well as serum levels of A-FABP, but the causal relationship needed to be clarified by further studies [26]. Even though, one systematic review showed controversial effects of statin on the reduction of aortic PWV [32], recent reports indicated that low dose of atorvastatin in mild HTN and hypercholesterolemia exerted beneficial effects on arterial stiffness and central aortic pressure [33]. In obese patients without glucose intolerance, treatment with PPAR alpha agonist (fenofibrate) revealed significant reduction in the augmentation index, PWV, and proinflammatory markers [34]. The results of subgroup analysis in this study suggest that ACEi, ARB, $\beta$-blockers, $\mathrm{CCB}$, statins, or fibrate had no influence at all, on arterial stiffness.

\section{Conclusions}

The major limitation of this study is that, this was a crosssectional study with a limited number of geriatric adults. Therefore, the findings of this study must be confirmed by long-term prospective studies before a causal relationship between the serum A-FABP and arterial stiffness can be established in the geriatric patient population. However, to the best of our knowledge, this is the first study to examine the relationship between serum A-FABP and arterial stiffness in the geriatric population. 
In conclusion, we found that serum A-FABP levels were higher in geriatric population having high arterial stiffness. More importantly, A-FABP may serve as an independent predictor for the development of arterial stiffness in geriatric adults. Whether serum A-FABP directly contributes to the development of arterial stiffness or not, needs to be further validated in larger cohorts.

\begin{abstract}
Abbreviations
A-FABP: Adipocyte fatty acid binding protein; ACEi: Angiotensin-converting enzyme inhibitor; ARB: Angiotensin receptor blocker; BMI: Body mass index; BP: Blood pressure; BUN: Blood urea nitrogen; CCB: Calcium channel blockers; cfPW: Carotid-femoral pulse wave velocity; DM: Diabetes mellitus; CVD: Cardiovascular disease; Cre: Creatinine; DBP: Diastolic blood pressure; eNOS: Endothelial nitric oxide synthase; GFR: Glomerular filtration rate; HDLcholesterol: High-density lipoprotein-cholesterol; HTN: Hypertension; IPTH: Intact parathyroid hormone levels; MDRD: Modification of diet in renal disease; LDL-cholesterol: Low-density lipoprotein cholesterol; SBP: Systolic blood pressure; TCH: Total cholesterol; TG: Triglyceride.
\end{abstract}

\section{Competing interests}

The authors declare that they have no competing interests.

\section{Authors' contributions}

JPT, CJL, and BGH designed this study, analyzed the data and wrote this manuscript. CJL and BGH performed the experiments of this study. JHW, CJL, YCC and BGH recruited patients. All authors read and approved the final manuscript.

\section{Acknowledgements}

This work was supported by grants from Buddhist Tzu Chi Hospital (TCRD 101-03) in Taiwan.

\section{Author details}

'Division of Nephrology, Buddhist Tzu Chi General Hospital, Dalin Branch, Chia-Yi, Taiwan. ${ }^{2}$ School of Medicine, Tzu Chi University, Hualien, Taiwan. ${ }^{3}$ Division of Cardiology, Buddhist Tzu Chi General Hospital, Hualien, Taiwan. ${ }^{4}$ Department of Nursing, Tzu Chi College of Technology, Hualien, Taiwan. ${ }^{5}$ Division of Nephrology, Buddhist Tzu Chi General Hospital, No. 707, Section 3, Chung-Yang Road, Hualien 97002, Taiwan.

Received: 7 April 2015 Accepted: 16 July 2015

Published online: 24 July 2015

\section{References}

1. Alan S, Ulgen MS, Ozturk O, Alan B, Ozdemir L, Toprak N. Relation between coronary artery disease, risk factors and intima-media thickness of carotid artery, arterial distensibility, and stiffness index. Angiology. 2003;54(3):261-7.

2. Vlachopoulos C, Aznaouridis K, Stefanadis C. Prediction of cardiovascular events and all-cause mortality with arterial stiffness: a systematic review and meta-analysis. J Am Coll Cardiol. 2010;55(13):1318-27.

3. Mahmud A, Feely J. Arterial stiffness is related to systemic inflammation in essential hypertension. Hypertension. 2005;46(5):1118-22.

4. Laurent S, Boutouyrie P, Lacolley P. Structural and genetic bases of arterial stiffness. Hypertension. 2005;45(6):1050-5.

5. Mancia G, Fagard R, Narkiewicz K, Redon J, Zanchetti A, Bohm M, et al. 2013 ESH/ESC Guidelines for the management of arterial hypertension: the Task Force for the management of arterial hypertension of the European Society of Hypertension (ESH) and of the European Society of Cardiology (ESC). J Hypertens. 2013;31(7):1281-357.

6. Makowski L, Hotamisligil GS. Fatty acid binding proteins-the evolutionary crossroads of inflammatory and metabolic responses. J Nutr. 2004;134(9):2464S-8S.

7. Fisher RM, Eriksson P, Hoffstedt J, Hotamisligil GS, Thorne A, Ryden M, et al. Fatty acid binding protein expression in different adipose tissue depots from lean and obese individuals. Diabetologia. 2001;44(10):1268-73.

8. Lee MY, Li H, Xiao Y, Zhou Z, Xu A, Vanhoutte PM. Chronic administration of BMS309403 improves endothelial function in apolipoprotein E-deficient mice and in cultured human endothelial cells. Br J Pharmacol. 2011;162(7):1564-76.

9. Tsai JP, Liou HH, Liu HM, Lee CJ, Lee RP, Hsu BG. Fasting serum fatty acid-binding protein 4 level positively correlates with metabolic syndrome in hemodialysis patients. Arch Med Res. 2010;41(7):536-40.

10. Hsu BG, Chen YC, Lee RP, Lee CC, Lee CJ, Wang JH. Fasting serum level of fatty-acid-binding protein 4 positively correlates with metabolic syndrome in patients with coronary artery disease. Circ J. 2010;74(2):327-31.

11. Avolio AP, Chen SG, Wang RP, Zhang CL, Li MF, O'Rourke MF. Effects of aging on changing arterial compliance and left ventricular load in a northern Chinese urban community. Circulation. 1983;68(1):50-8.

12. Alberti KG, Zimmet PZ. Definition, diagnosis and classification of diabetes mellitus and its complications. Part 1: diagnosis and classification of diabetes mellitus provisional report of a WHO consultation. Diabet Med. 1998;15(7):539-53.

13. Wang JH, Lee CJ, Hsieh JC, Chen YC, Hsu BG. Serum atrial natriuretic peptide level inversely associates with metabolic syndrome in older adults. Geriatr Gerontol Int. 2014;14(3):640-6.

14. Wang JH, Lee CJ, Chen ML, Yang CF, Chen YC, Hsu BG. Association of serum osteoprotegerin levels with carotid-femoral pulse wave velocity in hypertensive patients. J Clin Hypertens. 2014;16(4):301-8.

15. Lee CJ, Wang JH, Chen YC, Chen ML, Yang CF, Hsu BG. Serum osteopontin level correlates with carotid-femoral pulse wave velocity in geriatric persons. BioMed research international. 2014;2014:570698.

16. Cecelja M, Chowienczyk P. Dissociation of aortic pulse wave velocity with risk factors for cardiovascular disease other than hypertension: a systematic review. Hypertension. 2009;54(6):1328-36.

17. Laurent S, Boutouyrie P. Arterial stiffness: a new surrogate end point for cardiovascular disease? J Nephrol. 2007;20 Suppl 12:S45-50.

18. van Sloten $T$, Protogerou AD, Henry RM, Schram MT, Launer $\sqcup$, Stehouwer CD. Association between arterial stiffness, cerebral small vessel disease and cognitive impairment: a systematic review and meta-analysis. Neurosci Biobehav Rev. 2015;53:121-30.

19. Zhang Y, Agnoletti D, Xu Y, Wang JG, Blacher J, Safar ME. Carotid-femoral pulse wave velocity in the elderly. J Hypertens. 2014;32(8):1572-6. discussion 1576.

20. de Faria AP, Demacq C, Figueiredo VN, Moraes CH, Santos RC, Sabbatini AR, et al. Hypoadiponectinemia and aldosterone excess are associated with lack of blood pressure control in subjects with resistant hypertension. Hypertens Res. 2013;36(12):1067-72.

21. Sabbatini AR, Faria AP, Barbaro NR, Gordo WM, Modolo RG, Pinho C, et al. Deregulation of adipokines related to target organ damage on resistant hypertension. J Hum Hypertens. 2014;28(6):388-92.

22. Miyoshi T, Onoue G, Hirohata A, Hirohata S, Usui S, Hina K, et al. Serum adipocyte fatty acid-binding protein is independently associated with coronary atherosclerotic burden measured by intravascular ultrasound. Atherosclerosis. 2010;211(1):164-9.

23. Rhee EJ, Lee WY, Park CY, Oh KW, Kim BJ, Sung KC, et al. The association of serum adipocyte fatty acid-binding protein with coronary artery disease in Korean adults. Eur J Endocrinol. 2009;160(2):165-72.

24. Makowski L, Boord JB, Maeda K, Babaev VR, Uysal KT, Morgan MA, et al. Lack of macrophage fatty-acid-binding protein aP2 protects mice deficient in apolipoprotein E against atherosclerosis. Nat Med. 2001;7(6):699-705.

25. Hayashi K, Handa H, Nagasawa S, Okumura A, Moritake K. Stiffness and elastic behavior of human intracranial and extracranial arteries. J Biomech. 1980;13(2):175-84.

26. Miyoshi T, Doi M, Hirohata S, Kamikawa S, Usui S, Ogawa H, et al. Olmesartan reduces arterial stiffness and serum adipocyte fatty acid-binding protein in hypertensive patients. Heart Vessel. 2011;26(4):408-13.

27. Yeung DC, Xu A, Tso AW, Chow WS, Wat NM, Fong CH, et al. Circulating levels of adipocyte and epidermal fatty acid-binding proteins in relation to nephropathy staging and macrovascular complications in type 2 diabetic patients. Diabetes Care. 2009;32(1):132-4.

28. Schram MT, Henry RM, van Dijk RA, Kostense PJ, Dekker JM, Nijpels $G$, et al. Increased central artery stiffness in impaired glucose metabolism and type 2 diabetes: the Hoorn Study. Hypertension. 2004;43(2):176-81.

29. Protogerou A, Blacher J, Stergiou GS, Achimastos A, Safar ME. Blood pressure response under chronic antihypertensive drug therapy: the role of aortic stiffness in the REASON (Preterax in Regression of Arterial Stiffness in a Controlled Double-Blind) study. J Am Coll Cardiol. 2009;53(5):445-51. 
30. Dhakam Z, McEniery CM, Yasmin, Cockcroft JR, Brown MJ, Wilkinson IB. Atenolol and eprosartan: differential effects on central blood pressure and aortic pulse wave velocity. Am J Hypertens. 2006;19(2):214-9.

31. Morgan T, Lauri J, Bertram D, Anderson A. Effect of different antihypertensive drug classes on central aortic pressure. Am J Hypertens. 2004;17(2):118-23.

32. Rizos EC, Agouridis AP, Elisaf MS. The effect of statin therapy on arterial stiffness by measuring pulse wave velocity: a systematic review. Curr Vasc Pharmacol. 2010;8(5):638-44.

33. Kanaki Al, Sarafidis PA, Georgianos PI, Kanavos K, Tziolas IM, Zebekakis PE, et al. Effects of low-dose atorvastatin on arterial stiffness and central aortic pressure augmentation in patients with hypertension and hypercholesterolemia. Am J Hypertens. 2013:26(5):608-16.

34. Ryan KE, McCance DR, Powell L, McMahon R, Trimble ER. Fenofibrate and pioglitazone improve endothelial function and reduce arterial stiffness in obese glucose tolerant men. Atherosclerosis. 2007;194(2):e123-130.

\section{Submit your next manuscript to BioMed Central and take full advantage of:}

- Convenient online submission

- Thorough peer review

- No space constraints or color figure charges

- Immediate publication on acceptance

- Inclusion in PubMed, CAS, Scopus and Google Scholar

- Research which is freely available for redistribution 